\title{
The guiding evidence based therapy using biomarker intensified treatment in heart failure (GUIDE-IT) study; the utility of decongestive diuresis in type 1 cardiorenal syndrome with rising pro-BNP levels
}

\author{
Macaulay Amechi Chukwukadibia Onuigbo ${ }^{1,2,3}$ \\ ${ }^{1}$ Mayo Clinic College of Medicine, Rochester, MN, USA \\ ${ }^{2}$ Department of Nephrology, Mayo Clinic Health System, Eau Claire, WI, USA \\ ${ }^{3}$ College of Business, University of Wisconsin MBA Consortium, Wisconsin, USA
}

\section{A R T I C L E I N F 0}

Article Type:

Epidemiology and Prevention

\section{Article History:}

Received: 10 October 2017

Accepted: 9 December 2017

ePublished: 31 December 2017

\section{Keywords:}

Amino-terminal pro-B-type natriuretic peptide (NT-proBNP), Biomarker,

Cardiorenal syndrome,

Decongestive diuresis,

Heart failure

\begin{abstract}
A B S T RA C T
Implication for health policy/practice/research/medical education:

The Guiding Evidence Based Therapy Using Biomarker Intensified Treatment in Heart Failure (GUIDE-IT) study, a randomized clinical trial of nearly 1000 patients with heart failure and reduced ejection fraction, compared amino-terminal pro-B-type natriuretic peptide (NT-proBNP)-guided treatment strategy versus usual care. The study failed to show any differences in the primary end point of the composite of time-to-first heart failure hospitalization or cardiovascular mortality. Remarkably, despite the proBNPguided titration in the intervention group, there were no significant differences in medical therapy over time, between the two groups in relation to percentage exposure to the ACEI/ARB at 12 months. We had recently shown in a small case series that rising BNP levels at presentation in patients with type 1 cardiorenal syndrome portended improved cardiorenal outcomes as well as responsiveness to combination diuretics or decongestive diuresis. Further larger studies of these observations are warranted.

Please cite this paper as: Onuigbo MAC. The guiding evidence based therapy using biomarker intensified treatment in heart failure (GUIDE-IT) study; the utility of decongestive diuresis in type 1 cardiorenal syndrome with rising pro-BNP levels. J Nephropharmacol. 2018;7(2):66-67.
\end{abstract}

$\mathrm{W}$ e read with interest the just published report of The Guiding Evidence Based Therapy Using Biomarker Intensified Treatment in Heart Failure (GUIDE-IT) study (1). In this randomized clinical trial of nearly 1000 patients with heart failure and reduced ejection fraction, amino-terminal pro-Btype natriuretic peptide (NT-proBNP)-guided treatment strategy versus usual care failed to show any differences in the primary end point of the composite of time-to-first heart failure hospitalization or cardiovascular mortality (1). Furthermore, none of the secondary end points and the decreases in the NT-proBNP levels achieved differed significantly between the groups (1).

Remarkably, despite the proBNP-guided titration in the intervention group, there were no significant differences in medical therapy over time, between the two groups in relation to percentage of patients taking ACE/ARB, mean dose of ACE/ARB achieved, and percentage of patients taking $50 \%$ of target dose or $100 \%$ of target dose of ACE/
ARB at 12 months. The same absence of a significant difference between the two groups was observed for patients taking a mineralocorticoid antagonist (MRA), and patients taking $50 \%$ and $100 \%$ of target dose of MRA, respectively (1). Similarly, the mean dose of loop diuretics in the intervention group versus the control group at the 12 months was $86 \mathrm{mg}$ vs $77 \mathrm{mg}, P=0.26$. Moreover, baseline serum creatinine in both groups was similar - 1.3 $(1.1-1.7) \mathrm{mg} / \mathrm{dL}$.

From the foregoing analysis of the concurrent therapies applicable to both patient groups at 12 months, the findings of the GUIDE-IT study would therefore not be surprising since both patient groups were indeed similarly treated with regards to angiotensin converting enzyme inhibitor/ angiotensin receptor blocker, mineralocorticoid receptor antagonists (MRA) and loop diuretics. Likewise, patients in the biomarker-guided therapy group and patients in the usual care group achieved comparable reductions in NT-proBNP levels with time (1). In a related matter, we 
recently published in a case series in the Journal of Clinical Medicine, evidence to suggest that in patients with type 1 cardiorenal syndrome presenting with/without worsening renal failure, the presence of acutely rising BNP levels, on admission to the hospital, portended a good cardiorenal prognosis vis-a-vis individual patient responses to the intravenous loop diuretic, Furosemide, continuously infused, in combination with the co-administration of intravenous chlorothiazide, given in boluses every eight hours (2).

The utility of combination intravenous furosemidechlorothiazide in "decongestive diuresis" in such patients is clearly an available, affordable and cheap alternative therapeutic option that would be available virtually in very hospital setting all over the world, when compared to mechanical ultrafiltration with dialysis or related equipment (2). Further larger studies of this phenomenon are warranted to confirm our findings (2).

\section{Author's contribution}

MACO is the single author of the manuscript.

\section{Conflicts of interest}

The author report no conflicts of interest. The author alone are responsible for the content and writing of the article.

\section{Ethical considerations}

Ethical issues (including plagiarism, data fabrication, double publication) have been completely observed by the author.

\section{Funding/Support}

None.

\section{References}

1. Felker GM, Anstrom KJ, Adams KF, Ezekowitz JA, Fiuzat $\mathrm{M}$, et al. Effect of natriuretic peptide-guided therapy on hospitalization or cardiovascular mortality in high-risk patients with heart failure and reduced ejection fraction: a randomized clinical trial. JAMA. 2017;318:713-20. doi: 10.1001/jama.2017.10565.

2. Onuigbo M, Agbasi N, and Sengodan M, Rosario K. Acute kidney injury in heart failure revisited - the ameliorating impact of "decongestive diuresis" on renal dysfunction in type 1 acute cardiorenal syndrome: accelerated rising Pro $\mathrm{B}$ naturetic peptide is a predictor of good renal prognosis. J Clin Med. 2017;6. doi: 10.3390/jcm6090082.

Copyright $\odot 2018$ The Author(s); Published by Society of Diabetic Nephropathy Prevention. This is an open-access article distributed under the terms of the Creative Commons Attribution License (http://creativecommons.org/licenses/by/4.0), which permits unrestricted use, distribution, and reproduction in any medium, provided the original work is properly cited. 